\title{
Occupational Exposure to Biological Agents
}

\author{
Joana Santos ${ }^{1(\bowtie)}$, Carla Ramos ${ }^{1}$, Manuela Vaz-Velho ${ }^{1}$, \\ and Marta Vasconcelos Pinto ${ }^{1,2}$ \\ ${ }^{1}$ CISAS, Escola Superior de Tecnologia e Gestão, Instituto Politécnico \\ de Viana do Castelo, Rua Escola Industrial e Comercial de Nun'Álvares, \\ 4900-347 Viana do Castelo, Portugal \\ \{joana, cramos, mvazvelho\}@estg.ipvc.pt, \\ martavasconcelos@estescoimbra.pt \\ 2 Instituto Politécnico de Coimbra, ESTESC-Coimbra Health School, \\ Saúde Ambiental, Coimbra, Portugal
}

\begin{abstract}
Biological risks were mentioned by the "European Agency for Safety and Health, at Work's Expert Forecast on Emerging Biological Risks related to Occupational Safety and Health", the second most important emerging risk. In an era when the "one health approach" is considered the right way to address public health issues occupational safety continues to look at biological agents as a minor issue compared to other agents. The food industry is known to be very committed to food safety assurance but less concerned with the safety of food operators unless they may compromise the quality of the food product. However, the focus on biological agents is essential not only due to air spread or contact with organic dust but we must not overlook another crucial aspect which is the antimicrobial resistance that may be associated with biological agents, nowadays one of the biggest threats to global health, food security and development.
\end{abstract}

Keywords: Biological agents $\cdot$ One health approach $\cdot$ Food industry · Antibiotic resistance

\section{Introduction}

In an era when the "one health approach" is considered the right way to address public health issues, occupational health continues to look at biological agents as a minor issue compared to other agents, although the former include microorganisms capable of causing infections, allergies and/or toxicity to humans, and their presence in the workplace implying an increased risk to workers. Biological risk assessment is usually neglected by the occupational health professionals due to the lack of systematized information about the biological agents involved in many work activities. The publication bias and a large amount of confounding factors don't help the risk assessment activity although, since microorganisms are omnipresent in the environment, exposure to biological agents in various contexts is inevitable. The occupational safety professional is always facing gaps in hazard assessment of the risks, engendered by biological agents, such as: (i) lack of information on biohazards in the workplace; (ii) lack of training of workers; (iii) lack of maintenance of ventilation systems/air conditioning/water systems, 
and; (iv) lack of knowledge of combined effect of biological and chemical agents. When biological agents are introduced into workplaces, as part of the process, for example in a biotechnology laboratory, workers usually show high levels of awareness of the biological hazards to which they are exposed, knowing and using correct protective measures. However, this level of consciousness does not exist in other workplaces where biological agents are present, as a core of the activities performed, but as contaminants.

Several studies focus on the theme of environmental contamination by bacteria, fungi and their metabolites, seeking to establish a relationship between occupational exposure and the appearance of different symptoms among employees, but the role of biological agents in disease development and worsening of symptoms of workers is poorly understood since it is not entirely clear which components are really responsible for the health effect [1-4].

\section{Exposition to Biological Agents}

It is consensual that biological agents are microorganisms, including genetically modified, human cell cultures and endoparasites that may cause infection, allergies or toxicity. Although the term biological agent is very comprehensive universally, when addressing the theme "biological risk" attention focuses on the following elements: bacteria, fungi, viruses and parasites. These pathogens can be transmitted from a variety of sources: human, animals and environmental sources and can be acquired through inhalation, ingestion, skin and mucous membranes and the placenta. Humans have a variety of bacterial, fungal and viral infections that are transmitted from person to person through body fluids (hepatitis through a needle stick, as an example), secretions (tuberculosis through sneezing or coughing) and cross-contamination on surfaces (influenza virus, through touch on the nose and subsequent contamination of surfaces). From animal sources, occur severe infections of fungal, bacterial and viral origin, which are transmitted through contact with animals (animal-to-person) (e.g. rabies and leptospirosis) named zoonosis. From environmental sources (e.g. water, soil, air) and related to exposure to biological agents' diseases such as Legionnaire's, dust mites' allergies, etc. can be transmitted. The transmission and infection pathways are identified and the basic mechanism of infection is through the direct passage from the reservoir to the host, the prevention involves cutting the chain of transmission.

Biological agents can be classified into four risk groups, according to their level of pathogenicity, virulence, transmission, existence of effective prophylactic measures, the availability of effective treatment and others, depending on the country and/or organization [5] (e.g. World Health Organization, Canada, European Union (EU), European Federation of Biotechnology). In EU the Biohazard Prevention is mandatory [6] but there are several challenges regarding biological agents that should be considered: (i) the diversity of agents involved; (ii) they are not visible to the naked eye; (iii) the occupational exposure limits are not defined; (iv) they are a hazardous at very low concentrations; (v) the toxic effect exist due to metabolites they produce; (vi) reproduce themselves, (vii) rapid mutation, (viii) incubation period and infectiousness and rapid multiplication. 
Bioaerosols are considered the main responsible for the mobility of microorganisms by air. According to Cox and Wathes (1995), bioaerosols are fully defined as a collection of aerosol-shaped biological particles. However, exposure to bioaerosols and dust is not the only risk factor to consider, and the transmission of biological agents can be effective through contact with surfaces [2, 7, 8]. Microorganisms, including pathogens that cause disease in humans, can be transmitted from one location to another in various forms. The transmission of disease agents may be carried by droplets, direct contact or indirect contact [9]. However, inhalation represents the main route of exposure related to adverse effects on human health, being the most relevant in the occupational context [10]. The effects related to exposure to biological agents are diverse as: irritant effect (eyes, nose, throat and skin); toxic reactions (mycotoxins, endo and exotoxins); allergic Reactions (Rhinitis, Sinusitis, Asthma) and Infections (Legionnaires Disease, Tuberculosis, Pneumonia, Cryptococcosis) [1].

\section{Air Sampling Methods}

Bioaerosol sampling involves the removal and collection of particles of biological origin from the atmosphere [11]. There is a considerable variety of bioaerosol sampling and analysis methods. But there are several limitations, including the lack of standardized methods and protocols that are effective in sampling and analyzing all types of bioaerosols $[12,13]$. Therefore, comparing results between research studies becomes a difficult task due to the use of substantially different sampling and analysis methods.

The methods more commonly used for bioaerosol sampling are: impact, that promotes particle separation from a forced air stream and uses particle inertia to force deposition on a solid, semi-solid or liquid collection surface; filtration, that captures airborne particles that are trapped in a porous material as air passes through it and the sampling is done using different filters with different constitution and porosity, with the main objective of sampling different particle sizes; and sedimentation, that uses gravity to quantify sediment particles on adhesive surfaces. This last method is a nonquantitative method recurrently used due to its simplicity and low cost, a plate with nutrient medium that will identify the colonies arising from the growth of spores retained during the time of exposure to air.

All methods used for surface sampling have limitations, but those commonly used are: contact plates; swabs, tape, dust collection and material collection.

\section{Biological Risks Related to Occupational Safety and Health}

In 2007, biological risks were mentioned by the "European Agency for Safety and Health, at Work's Expert Forecast on Emerging Biological Risks related to Occupational Safety and Health" [14], the second most important emerging risk. Once the state of knowledge about biological hazards is still relatively immature, the development of methodologies for research and counting of biological agents and the harmonization of methodologies so that laboratory comparison can exist, urges. 
The first emerging risk identified in the above-mentioned report was Occupational Risks Related to Global Epidemics: SARS - Acute Respiratory Syndromes: Bird Flu, Cholera, and Yellow Fever. Several risk factors are associated with increased outbreaks, such as globalization together with social changes, intercontinental traveling of humans and animals influencing both the geographical distribution and abundance of ticks and pathogens [15], and the ability of microorganisms to adapt to behavioural factors and environmental changes (climate change).

Healthcare workers, workers in contact with animals, laboratory workers and refuse workers seem to have the highest risk of infection by a variety of pathogens [16]. As more than three quarters of these diseases are zoonoses, workers at risk are those who are in contact with infected live or dead animals with aerosols, dust or surfaces contaminated by animal secretions, in animal trade, breeding and slaughtering units, operators cleaning and disinfecting contaminated areas, veterinary services, research laboratories, customs, zoos and pet stores.

\subsection{Transmission of Biological Agents in Occupational Environment- Agriculture and the Food Processing Industry}

Regarding agriculture and farmers, there are several studies and, more recently, some studies have focused on this aspect namely the use of microalgae with the ability to biosynthesize a number of metabolites that can be considered biological agents for the control of organisms harmful to soil and plants [17] but that can indirectly affect man. A recent study on perception, knowledge and preventive measures by agricultural workers, despite the high probability of exposure to biological agents, revealed the lack of perception and knowledge of the risk, as well as the poor awareness of available preventive measures among agricultural worker [18]. An epidemiological study on occupational diseases among farmers conducted in Poland in 2016 demonstrated the need to introduce periodic health examinations programs focusing on agricultural workers to monitor health and well-being and improve working conditions and the working environment [19].

The food industry is known to be very committed to food safety assurance but less concerned with the safety of food operators unless they may compromise the quality of the food product. It is common in studies on occupational risk assessment of the food industry that the perspective of zoonosis as a source of risk is not referenced in occupational health and safety plans. In the latest report from the European Food Safety Authority of 2018 zoonoses are among the most common foodborne diseases (commonly referred to as food poisoning) and can also be spread to humans either by direct contact with a sick animal or by contact with a vector (or carrier) [20]. However, the focus on of biological agents is essential in food processing industry namely in activities such as slaughterhouses and poultry and meat processing industries not only due to air spread or contact with organic dust. However, we must not overlook another crucial aspect which is the antimicrobial resistance that may be associated with biological agents, nowadays one of the biggest threats to global health, food security and development [21, 22]. Risk assessment in professional activities, where exposure to biological agents can be frequent and intense, considers the potential levels of exposure, and the level of infectious risk of the potentially existing agents. However, current 
risk assessment models are inadequate to evaluate the effect of antibiotics and antibiotic resistance genes (ARGs) on resistance emergence and selection, especially in nonclinical environments [23]. Biological risk assessment has become even more complex because, in addition to detecting biological agents with potential for risk for workers, it is necessary to assess the antimicrobial resistance that can be seen to bring to the workplaces being an aggravated danger to public health issues. The emergence of antimicrobial-resistant bacteria in mass animal husbandry has raised further concern regarding occupational exposure and its potential public health consequences. Particular attention has been paid to methicillin-resistant Staphylococcus aureus (MRSA) and multidrug-resistant Gram-negative enteric pathogens (GNEP) [24-27].

\section{Conclusion}

The state of knowledge about biological risks in work environments is still relatively immature. Publication bias, a large number of confounding factors and the lack of harmonization of methodologies to research and count biological agents is notorious. This brings another problem to the occupational health professionals in addition to the nonexistence of exposure limit values for biological agents. Since the presence of gram-negative bacteria is the most health-relevant concern due to the presence of endotoxins, the detected bacteria should also be categorized according to gram stain and their antimicrobial resistance evaluated when appropriate. In conclusion there is a need to develop uniform and concise guidance on risk assessment of biological risks (e.g. sampling, harmonization of methodologies for analysis of biological agents). The list of classifications of biological agents should be reevaluated and the information on the dose-effect would also help to establish occupational exposure limits at least for the most common microorganisms.

\section{References}

1. Douwes, J., Thorne, P., Pearce, N., Heederik, D.: Bioaerosol health effects and exposure assessment: progress and prospects. Ann. Occup. Hyg. 47(3), 187-200 (2003)

2. Corrao, C.R., Mazzotta, A., La Torre, G., De Giusti, M.: Biological risk and occupational health. Ind. Health 50(4), 326-337 (2012)

3. Dutkiewicz, J., Cisak, E., Sroka, J., Wojcik-Fatla, A., Zajac, V.: Biological agents as occupational hazards - selected issues. Ann. Agric. Environ. Med. 18(2), 286-293 (2011)

4. Dutkiewicz, J., Jablonski, L., Olenchock, S.A.: Occupational biohazards - a review. Am. J. Ind. Med. 14, 605-623 (1988)

5. International classifications schemes for micro-organisms based on their biological risks. https://www.biosafety.be/content/contained-use-international-classifications-schemes-microorganisms-based-their-biological

6. Directiva 2000/54/CE do Parlamento Europeu e do Conselho de 18 de Setembro de 2000 relativa à protecção dos trabalhadores contra riscos ligados à exposição a agentes biológicos durante o trabalho. J. Oficial da Comunidades Europeias L 262, 0021-0045 (2000)

7. Montano, D.: Chemical and biological work-related risks across occupations in Europe: a review. J. Occup. Med. Toxicol. 9(28), 1-13 (2014) 
8. Wan, M.P.: Modeling the pathogen exposure and infection risk associated with fomite transmission in an aircraft cabin mock-u. In: 2nd International ISCM Symposium and the 12th International EPMESC Conference, pp. 1576-1582. American Institute of Physics (2010)

9. Tortora, G.J., Funke, B.R., Case, C.L., (eds.): Microbiologia. 6th edn. Artes Médicas Sul, Porto Alegre (2000)

10. Stetzenbach, L.D.: Introduction to aerobiology. In: Hurst, C.J., Crawford, R.L., Knudsen, G. R., McInerney, M.J., Stetzenbach, L.D. (eds.) Manual of Environmental Microbiology, 2nd edn, pp. 801-813. ASM Press, Washington DC (2002)

11. Pillai, S.D., Ricke, S.C.: Bioaerosols from municipal and animal wastes: background and contemporary issues. Can. J. Microbiol. 48(8), 681-696 (2002)

12. Goyer, N., Lavoie, J., Lazure, L., Marchand, G.: Bioaerosols in the workplace: evaluations. In: Control and Prevention Guide, Québec (2001)

13. Buttner, M., Willeke, K., Grinshpun, S.: Sampling and analysis of airborne microorganisms. In: Hurst, C.J., Crawford, R.L., Knudsen, G.R., McInerney, M.J., Stetzenbach, L.D. (eds.) Manual of Environmental Microbiology, pp. 814-826. ASM Press, Washington DC (2002)

14. Emmanuelle, B.: Expert forecast on emerging biological risks related to occupational safety and health. European Agency for Safety and Health at Work (2007). https://osha.europa.eu/ en/publications/reports/7606488

15. Medlock, J.M., Hansford, K.M., Bormane, A., Derdakova, M., Estrada-Pena, A., George, J. C., Golovljova, I., Jaenson, T.G.T., Jensen, J.K., Jensen, P.M., et al.: Driving forces for changes in geographical distribution of Ixodes ricinus ticks in Europe. Parasites Vectors 6 (2013). https://doi.org/10.1186/1756-3305-6-1

16. Haagsma, J.A., Tariq, L., Heederik, D.J., Havelaar, A.H.: Infectious disease risks associated with occupational exposure: a systematic review of the literature. Occup. Environ. Med. 69, 140-146 (2012)

17. Costa, J.A.V., Freitas, B.C.B., Cruz, C.G., Silveira, J., Morais, M.G.: Potential of microalgae as biopesticides to contribute to sustainable agriculture and environmental development. J. Environ. Sci. Health B 54, 366-375 (2019)

18. Tamburro, M., Anzelmo, V., Bianco, P., Sammarco, M.L., Ripabelli, G.: Biological risk in agriculture and construction workplaces: a survey on perception, knowledge and prevention measures. G. Ital. Med. Lav. Ergon. 40, 195-202 (2018)

19. Szeszenia-Dabrowska, N., Swiatkowska, B., Wilczynska, U.: Occupational diseases among farmers in Poland. Med. Pr. 67, 163-171 (2016)

20. EFSA and ECDC: The European Union One Health 2018 Zoonoses Report. EFSA J. (2019)

21. Antibiotic Resistance: World Health Organization. https://www.who.int/news-room/factsheets/detail/antibiotic-resistance

22. Anderson, M., Clift, C., Schulze, K., Sagan, A., Nahrgang, K., Ait Ouakrim, D., Mossialos, E.: European observatory on health systems and policies. In: Policy Brief 32. World Health Organization (2019)

23. Berendonk, T.U., Manaia, C.M., Merlin, C., Fatta-Kassinos, D., Cytryn, E., Walsh, F., Burgmann, H., Sorum, H., Norstrom, M., Pons, M.N., et al.: Tackling antibiotic resistance: the environmental framework. Nat. Rev. Microbiol. 13, 310-317 (2015)

24. Alba, P., Feltrin, F., Cordaro, G., Porrero, M.C., Kraushaar, B., Argudin, M.A., Nykasenoja, S., Monaco, M., Stegger, M., Aarestrup, F.M., et al.: Livestock-associated methicillin resistant and methicillin susceptible Staphylococcus aureus sequence type (CC) 1 in European farmed animals: high genetic relatedness of isolates from Italian cattle herds and humans. PLoS ONE 10, 1-10 (2015) 
25. Peeters, L.E.J., Argudin, M.A., Azadikhah, S., Butaye, P.: Antimicrobial resistance and population structure of Staphylococcus aureus recovered from pigs farms. Vet. Microbiol. 180, 151-156 (2015)

26. Butaye, P., Argudin, M.A., Smith, T.C.: Livestock-associated MRSA and its current evolution. Curr. Clin. Microbiol. Rep. 3, 19-31 (2016)

27. Mehndiratta, P.L., Bhalla, P.: Use of antibiotics in animal agriculture \& emergence of methicillin-resistant Staphylococcus aureus (MRSA) clones: need to assess the impact on public health. Indian J. Med. Res. 140, 339-344 (2014) 